\title{
A Spanish revival
}

Spain's Ministry of Science and Innovation was re-established in April, four years after its dissolution in 2004. Cristina Garmendia, a former molecular biologist and chief executive of the Genetrix group of biotech companies, heads the new ministry.

\begin{abstract}
Why is the ministry putting so much emphasis on innovation?

We want to strengthen the chain of

knowledge from its generation in universities and public research bodies, to the stage where it translates into a benefit to society in the form of products and services. The ministry has taken on responsibility for the main areas involved in this chain, with the goal of promoting the creation of technology-based companies. Biomedical research centres, which were managed by the Ministry of Health, are also now under the Ministry of Science.
\end{abstract}

\section{The decision to move universities} from the education ministry has been controversial. Some fear that they will be pressured by business interests.

This is not true. Of course, we have to preserve blue-sky research at universities, but we must also favour a system that makes them sustainable and improves their financing. This is not at all at odds with maximizing knowledge transfer to society. To include universities in the Ministry of Science makes sense because they have a key role in the Spanish research and development (R\&D) system.

\section{How will the long-awaited new law make Spanish science more flexible and internationally competitive? \\ The legislative reform will result in a new Law of Science and Technology that will give more autonomy to public research bodies and reduce bureaucracy. Changes will also be made to other laws that hinder the flexibility and internationalization of Spanish R\&D.}

\section{What sort of changes?}

For example, it will be simpler to apply for scientific grants. And there will be changes to immigration laws so that foreign researchers can work here more easily. Other modifications will help researchers move between the public and private sectors. We are going to introduce the new law, which has cross-party support, to the House of Representatives in the first semester of 2009.

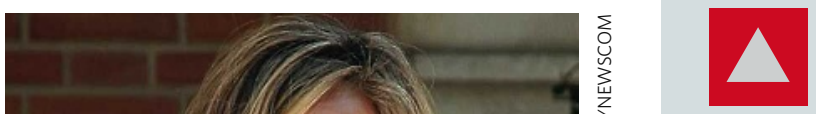

\section{SCORECARD}

Mercury rising NASA's Messenger mission has resolved a mystery about the planet closest to the Sun: its flat plains were formed by volcanic activity.

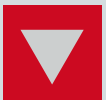

Mercury falling Messenger also found that the radius of the 4-billion-year-old planet has shrunk by several kilometres as Mercury's core has cooled.

\section{NUMBER CRUNCH}

10,000 people have been called in to help rid Chinese waters of an algal bloom threatening the Olympic sailing site.

285,000 tonnes of the bluegreen algae have been removed from the water so far.

430 kilometres is the distance from Beijing of a potentially devastating swarm of locusts.

science is low investment from the private sector. How will the ministry tackle that?

At the moment, investment in R\&D coming from the private sector is only about $55 \%$, well below the European average. We hope to raise this to $66 \%$. To do this, we must convince Spanish-based businesses, many of which are investing in $\mathrm{R} \& \mathrm{D}$ projects abroad, to change their practices and stay at home. We are talking with the Confederation of Spanish Industry, the Spanish chambers of commerce and employers all over Spain. To judge from the number of requests for meetings with the ministry, the private sector is very interested in the new initiatives.

\section{How will this be encouraged?}

We are offering incentives to make investment in $\mathrm{R} \& \mathrm{D}$ more attractive. And we are pledging full commitment in five sectors in which we wish Spain to become an international leader: health, biotechnology, nanotechnology and nanoscience, renewable energies and information technology. Interview by Cristina Jimenez

See Naturejobs, page 248.
1 month remains until the Olympic Games begin.

\section{ZOO NEWS}

\section{Spot the difference}

A system has been developed to identify and monitor individual penguins by analysing the tiny spots on their white chests. The researchers aim to use the system on other animals too; it should work on leopards because they can't change their spots either.

Sources: People, Science, Xinhua

News, spotthepenguin.com

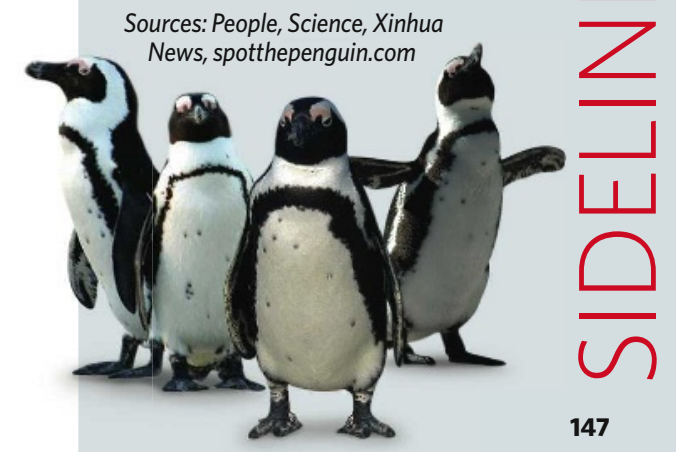

